\title{
Exploring the Likelihood of a Country Being a Tax Haven Using MIMIC Models
}

\author{
Paulo Reis Mourao** \\ *Department of Economics, University of Minho, Portugal
}

Submitted: September 6, $2019 \bullet$ Accepted: December 12, 2019

\begin{abstract}
The multiple indicators multiple causes (MIMIC) framework is used to analyze dimensions related to causation and indicators of tax haven status. Robust results were obtained that identify a country's tax burden and area as causes of a country adopting policies usually observed in tax havens. The level of social security contributions as a proportion of public revenues and the ratio of indirect to direct taxes were found to be statistically significant indicators of tax havens. Data from 68 countries for more than twenty years were analyzed, enabling the results to contribute to a deepening of the current debate about tax havens and their socio-economic profiles.
\end{abstract}

JEL classification: E44, E60, C51

Keywords: tax havens; MIMIC models; public finances; statistical models

\section{Introduction}

Classifying a country as a "tax haven" is not a task to be taken lightly. There are reputational problems that arise from labeling an economy as a tax haven. Furthermore, to undertake the classification, researchers must account for a multitude of socio-economic factors that change over time.

*Address: University of Minho, Braga, Portugal, 4700. Email: paulom@eeg.uminho.pt 
The study of tax havens has been based on three main dimensions. The first dimension relates to the worldwide consequences of tax haven practices, namely the ultimate consequences for the global financial system (Faith, 1984, Burn, 2006). The second dimension relates to the determinants that move a country to be classified as a tax haven as compared to an offshore location (Dharmapala and Hines Jr, 2009). The third dimension is associated with the suggested policies for regulating the practices of tax havens and offshores (Chavagneux and Palan, 2007). Keeping these three dimensions in mind, it was not possible to find a comprehensive set of empirical studies focused on the public finances of tax havens.

This paper introduces the potential uses of multiple indicators multiple causes (MIMIC) models. These models approach the problem of measurability issues (e.g., the shadow economy or the propensity of a country to adopt a tax haven profile) as a latent variable problem. MIMIC models also allow the testing of the statistical significance of the causes of the latent dimension as well its indicators and consequences (Dybka et al. 2019$)$. Therefore, this paper investigates for the first time, with the use of a MIMIC model, what are the driving factors of tax havens and in which indicators are tax havens reflected.

According to the OECD (2000), about half of international financial flows pass through tax havens. Maurer (1997) also observed that tax havens create local jobs and increase public revenues. The financial systems in tax haven economies tend to be more dynamic, also suggesting that the tax haven option leads to positive effects on local societies. However, the methodological potentialities of working with latent dimensions (namely, a 'hidden' pressure from dynamic neighboring countries or political goals toward rapid growth) have not been properly explored in the literature. Therefore, the intent of this paper is to enrich the debate around the identification of tax havens.

Based upon a literature review, as "causes" of tax haven status, I analyze such variables as the level of taxation as a percentage of GDP and mass dimensions (millions of resident persons; the area of an identified territory) as well as trade openness and GDP growth. As "indicators" reflecting the likelihood that a territory is a tax haven, I consider the ratio of social contributions to public revenues, the level of indirect taxation, the level of taxes on goods and services, the corruption perception index, and the weight of interest payments in budgetary expenses.

The remainder of this work is composed of a review of the literature (Section 2) which details the causes and the indicators of tax havens as described in research papers. Section 3 describes an empirical approach to the methodological discussion of MIMIC models including empirical procedures. Section 4 discusses the results and their robustness, and finally, Section 5 concludes the paper. 


\section{Causes and Indicators of Tax Havens}

When working with structural equation models, authors like Bollen and Brand (2008) use the term "cause" (or causal variable) to classify certain dimensions which have been associated in the literature with the observed phenomenon. It is relevant to note that this issue - the "tax havens" issue - is a complex phenomenon that cannot be simplified to a unidirectional relation of the type "A causes B". There are three major reasons why there are not simplistic causes of tax havens. The first reason relates to the meaning of the term itself. As is widely recognized nowadays, the expression "tax haven" is a label attributed to a certain economy by a given source. This means that we can study tax havens following the literature of taxonomy. Consequently, the label "tax haven" can be understood as a human construction limited to a certain reality assumed by certain agents. This means that other sources may label the same reality with a different name or expression (Robinson, 1994). The second reason is that the identification of an economy as a tax haven must be the result of a well-defined profile for an area. We cannot just classify a jurisdiction as a tax haven because it has reduced its tax rates for a period making them more interesting than the neighbors' tax rates. This would be similar to classifying someone as a violent individual because he/she had talked louder than others on a single occasion. Finally, tax havens may be studied as a "dynamic set of social and economic dimensions" which, for a proper time track, may be correlated with the exhibition/revelation of certain indicators (Faith, 1984).

After this necessary initial explanation of the complex nature of the "causes of tax havens", I now proceed to a review of the literature focused on the set of dimensions that lead jurisdictions to adopt policies that bring them closer to the profile of a tax haven.

\subsection{Causes}

The several works focused on the history of tax havens and on the history of economic thought around tax havens tend to identify particular phases of development during two important moments of economic globalisation: the first occurred in the 19th century, with the expansion of capitalism; the second in the post-World War II period, with the creation of the eurodollar market in the 1950s (Chavagneux and Palan, 2007). It has only been over the last thirty years, however, that tax havens have grown exponentially in number and importance. The liberalization and deregulation of the financial sphere, which began in the early 1980s, have been discussed as major contributors to this growth (Mourao and Raposo, 2013). Therefore, we cannot neglect open trade as an important motivation for the development of tax havens in countries characterized by economies where exports and imports are of high importance.

Many of the territories classified as tax havens exhibit a low magnitude of "mass dimension" variables such as population size and area. Tax havens do not usually need a large local population, a large amount of land, or abundant natural resources. Therefore, 
I also consider mass dimension variables as causes. Several authors have discussed the rationale for this relationship. Mourao and Raposo (2013) argue that "small" jurisdictions' people tend to realize clearer the expected benefits from the policies that move them toward the status of tax haven; taking the reverse perspective, jurisdictions covering large areas tend to see delays in the expected benefits of a short-term shock (significant inflows of foreign investment, huge economic growth, or positive stimulus in the local employment). Similarly, the larger the population, the greater the difficulties in implementing the pro-tax haven policies.

Rikowski (2002) notes that some particular characteristics of national public finances (namely, the existence of modest collected revenues) may drive some countries to develop a profile close to the usual profile of a tax haven. In this vein, tax revenues that represent a low percentage of GDP can be considered a cause of the development of policies related to tax havens. Obviously, the composition and the size of public revenues are considered in light of the composition and size of public expenditures. Jurisdictions are unlikely to maintain public revenues at a level below that of public expenditures; the maintenance of budget deficits is not sustainable for a long period, as the literature has often discussed (Hines Jr, 2004). However, the maintenance of deficits below 1\%-2\% of GDP and, simultaneously, of public revenues at $30 \%$ or less of GDP, has been associated with fiscally competitive countries, particularly those widely known as tax havens (Dharmapala and Hines Jr, 2009).

Finally, tax haven status is used as a vehicle to rapidly boost small economies. Thus small, open, and highly deregulated economies usually take advantage of tax haven activities as a source of foreign direct investment and for the development of their banking systems. Therefore, even though tax havens can reduce the amounts of available money and taxable income in some (medium or large) countries, they can ultimately stimulate the economic growth of small jurisdictions. Therefore, the growth rates of countries must be checked as proxies for alternative causes of becoming tax havens.

\section{$2.2 \quad$ Indicators}

In the literature, the term 'indicators' refers to variables that change following the occurrence of the phenomenon being analyzed (Dell'Anno and Mourao, 2012). Therefore, when discussing indicators of tax havens we are interested in variables that have been observed to change after the adoption of tax haven policies.

Tax havens tend to use fiscal instruments to attract investments and investors. Given a limited number of taxpayers, to achieve fiscal attractiveness a tax haven tends to generate incentives for capital by lowering income tax rates. Avoiding a concentration of taxes on financial services, tax havens tend to create higher taxation on goods and services (Becker and Fuest, 2010). Therefore, a good indicator of a tax haven is a low ratio of public revenues to income taxes (Becker and Fuest, 2010).

Focusing on the taxation of goods and services, tax havens accentuate indirect taxes 
over direct taxes. Although previous studies have identified that this indicator is also associated with "fiscal illusion" (Dell'Anno and Mourao, 2012), authors such as Dharmapala and Hines $\mathrm{Jr}(2009)$ have observed that nations with a higher value of indirect taxes, as compared to direct taxes, tend to assume practices related to tax havens.

Although tax havens aim to lower direct taxation to enhance fiscal attractiveness and because of scale effects, they also exhibit a modest percentage of national income taxation for social security. To attract skilled workers, social security taxes tend to be reduced in countries identified as tax havens or offshores. Additionally, given the low influence of trade unions or lobbying groups, support for the welfare state tends to accompany this trend to lower social security taxation in tax havens, and is generally less significant than in other countries.

Looking at the public expenditures side of tax haven economies, there is a high proportion of expenses taken up by interest payments. As Hines Jr (2004) claimed, open economies like tax havens and offshores tend to manage high economic growth by raising indebtedness. In most tax havens, financial institutions are the core agents of the economy and this proximity of the financial sector to government decision making generates an accentuated exposure to indebtedness practices that raises interest expenses.

The expected effects on institutional issues, like fiscal transparency or the quality of democracy, are not clear. Dharmapala and Hines Jr (2009) commented that the success of tax havens is due to the protection of data related to investors and traders; this protection can mainly be guaranteed by processes that harm the traditional concepts of fiscal transparency (Biondo, 2012). However, most investors clearly prefer to allocate their investments in markets sustained by stable democratic institutions. Therefore, is it not possible to make a clear argument connecting tax havens with fiscal transparency, corruption perception or quality of democracy.

\section{Empirical Analysis}

As observed, the analysis of what is generally understood about tax havens confirms two primary claims. Firstly, tax havens are complex economies characterized by multiple causes as well as multiple results, which can be economic, social, and/or geographic. Secondly, there may exist "hidden" dimensions that link these characteristics of tax havens, and which cannot easily be measured by reported data. Therefore, the context points to MIMIC models as the most appropriate models for evaluating these complex relations. As several authors have argued, MIMIC models have methodological advantages over methods using instrumental variables, natural experiments, and other reduced form methods (Hair et al., 1998; Zellner, 1970; Jairo, 2008). These advantages can be summarized along three dimensions: MIMIC models do not neglect latent factors; MIMIC models explore the gains of structural equation modeling; and MIMIC models allow the differentiation of the nature of the involved variables (causes versus indicators). 
As Dell'Anno and Mourao (2012) have argued, MIMIC models constitute a particular case of a broader class of models identified as structural equation models (SEM), which are commonly used to model relationships between unobserved dimensions (Hair et al., 1998). MIMIC models have developed from the works of Zellner (1970) and Jöreskog and Goldberger (1975). They have been used in public finance (Dell'Anno and Mourao, 2012, Dell'Anno and Villa, 2013), in corporate finance (Chiarella et al., 1992, Jairo, 2008), and in the economics of institutions (Kuklys, 2004; Dreher et al., 2007).

MIMIC models are composed of two equations: a measurement equation (1) and a structural equation (2). The measurement equation can be described with the following matrix notation (Dell'Anno and Mourao, 2012):

$$
\underset{(d \times 1)}{y}=\underset{(d \times 1)(1 \times 1)}{\lambda} \underset{(d \times 1)}{F}
$$

In equation (1), $F$ identifies the unobserved latent variable, subject to the column vector of disturbances $\varepsilon$ and causing the endogenous indicators $y . \lambda$ is a (column) vector composed of the regression coefficients.

The structural equation relates $F$ (the unobserved variable) to a set $x$ of exogenous causes (Dell'Anno and Mourao, 2012).

$$
\underset{(1 \times 1)}{F}=\underset{(1 \times c)}{\beta^{\prime}} \underset{(c \times 1)}{x}+\underset{(1 \times 1)}{\varsigma}
$$

The structural disturbance is identified by $\varsigma$, and $\beta$ is a vector of coefficients describing the relationship between $F$ and the $x$ causes.

The MIMIC models assume that all the variables $(F, x, y)$ have have zero as the value for expected means (so the model uses de-meaned variables ${ }^{1}$ ). It is assumed that $E(\varsigma)=E(\varepsilon)=0$ and that error terms are not correlated with the causes: $E\left(x \varepsilon^{\prime}\right)=0$ and $E(x \varsigma)=0$. It is assumed that the error term $\varepsilon$ is not correlated with the latent variable $E\left(F \varepsilon^{\prime}\right)=0$ or the structural disturbance $E(\varepsilon \varsigma)=0$. The variance of the error term has been found to be positive in the software used for this analysis, STATA v.15.0 (note: this is contrary to some other statistical packages which would provide incorrect identification schemes).

Equations (1) and (2) are estimated by a maximum likelihood estimator. However, to obtain unique solutions to $\lambda$ and $\beta$ it is necessary to fix the scale of the unobserved variable by setting one of the coefficients in $\lambda$ to a constant (usually +1 or -1 ). For instance, Dell'Anno and Mourao (2012) set -1 as the measurement coefficient of the measurement equation with the highest $\mathrm{R}$-squared value.

The de-meaning of the variables makes it possible to consider heterogeneity across the (cross-sectional) units in the MIMIC model and to apply SEM using panel data analysis

\footnotetext{
${ }^{1}$ In this paper, this means that the variables imported into the model are deviations of the the respective country from the mean values of the variables for the sample period.
} 
(Bollen and Brand, 2008). This process means that instead of the raw variables $x$ and $y$, we use $x_{j i t}^{*}$ and $y_{j i t}^{*}$. That is, for the most general model there are $j=1,2, \ldots, 11$ observed variables; $i=1,2, \ldots, 68$ countries, and $t=1990, \ldots, 2015$. The raw variables are transformed into the de-meaned ones by:

$$
x_{j i t}^{*}=x_{j i t}-\bar{x}_{j i} \quad \text { and } \quad y_{j i t}^{*}=y_{j i t}-\bar{y}_{j i}
$$

Because of this standardization, the latent variable $F$ is also estimated as a de-meaned variable, in other words, the MIMIC model estimates a new $F_{i t}^{*}=F_{i t}-\bar{F}_{i}$. In this specific case, $F_{i t}^{*}$ represents an index of the likelihood of a country assuming the characteristics of a tax haven.

The sample used in this study consists of 68 countries: Australia, Austria, Belgium, Bolivia, Brazil, Bulgaria, Canada, Chile, Colombia, Costa Rica, Cyprus, the Czech Republic, Denmark, the Dominican Republic, Ecuador, El Salvador, Estonia, Fiji, Finland, France, Germany, Greece, Guatemala, Honduras, Hungary, Iceland, India, Ireland, Israel, Italy, Japan, Korea, Lithuania, Luxembourg, Madagascar, Malaysia, Mali, Mauritius, Mexico, Nepal, Netherlands, Nicaragua, Norway, New Zealand, Oman, Pakistan, Panama, Papua New Guinea, Paraguay, Peru, the Philippines, Poland, Portugal, Romania, Russia, Slovenia, South Africa, Spain, Sri Lanka, Sweden, Switzerland, Trinidad and Tobago, Turkey, the United Arab Emirates, the United Kingdom, Uruguay, the United States of America, and Venezuela. The years covered were 1990 through 2015 (this is the maximum length of time for which some variables are available for certain countries). Following several studies (Mourao, 2008; Dell'Anno and Mourao, 2012), these 68 economies have been reported as comprising a significant sample of the heterogeneous territories that can be identified now and in the observed period. This includes developing and developed economies, OECD and non-OECD countries, established and new political regimes, etc. Additionally, they have been found to allow a reasonable availability of data for a significant number of socio-economic indicators.

For the model in this paper, I estimated various specifications (Table 2). The most general specification of the MIMIC model is a MIMIC 5-1-6 (5 causes, 1 latent variable, 6 indicators). Therefore, for this specification, equation 1 can be rewritten using the 6 indicators:

$$
\begin{aligned}
& x_{1 i t}^{*}=\lambda_{1} F_{i t}^{*}+\varepsilon_{1 i t} ; \\
& x_{2 i t}^{*}=\lambda_{2} F_{i t}^{*}+\varepsilon_{2 i t} ; \\
& x_{3 i t}^{*}=\lambda_{3} F_{i t}^{*}+\varepsilon_{3 i t} ; \\
& x_{4 i t}^{*}=\lambda_{4} F_{i t}^{*}+\varepsilon_{4 i t} ; \\
& x_{5 i t}^{*}=\lambda_{5} F_{i t}^{*}+\varepsilon_{5 i t} ; \\
& x_{6 i t}^{*}=\lambda_{6} F_{i t}^{*}+\varepsilon_{6 i t} .
\end{aligned}
$$


and equation 2 can be rewritten using the 5 causes:

$$
F_{i t}^{*}=\beta_{1} x_{1 i t}^{*}+\beta_{2} x_{2 i t}^{*}+\beta_{3} x_{3 i t}^{*}+\beta_{4} x_{4 i t}^{*}+\beta_{5} x_{5 i t}^{*}+\varsigma_{i t}
$$

The following path diagram for the MIMIC 5-1-6 model concretizes the most general specification of this model.

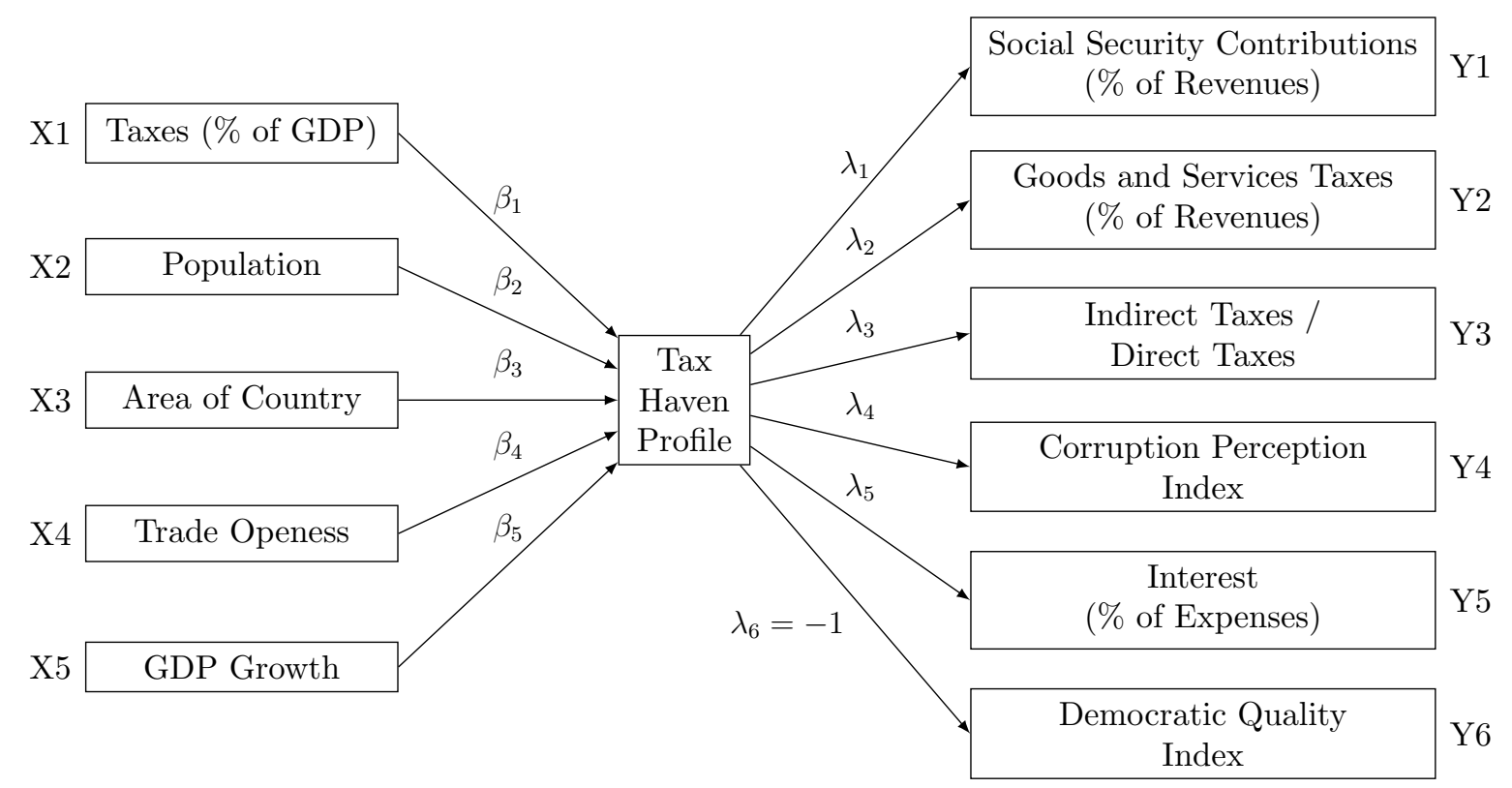

Figure 1: MIMIC diagram - Latent variable: Likelihood of being a tax haven

Table 2 displays the correlation matrix for the 10 variables being used as causes and indicators. The highest correlation coefficients relate to the correlation between the area of the country (size in $\mathrm{km}^{2}$ ) and trade openness or between the weight of taxes on GDP and trade openness.

Table 3 shows the results of estimating the different specifications of the MIMIC panel data models. Overall, we observe the following values for the RMSEA (root mean squared error of approximation): 0.06 (model 5-1-6), 0.07 (model 4-1-6), 0.08 (model 4-1-5), and 0.01 (model 4-1-4). The fourth model (4 causes and 4 indicators) is the most appropriate for further discussion given it has a lower RMSEA and higher $\mathrm{R}^{2}$. Values for other statistical tests such as the comparative fit index (CFI) or Tucker-Lewis index (TLI) are available upon request.

Recall that:

$$
x_{j i t}^{*}=x_{j i t}-\bar{x}_{j i} \quad \text { and } \quad y_{j i t}^{*}=y_{j i t}-\bar{y}_{j i} .
$$

A special cautionary note is needed in explaining the "marginal effects" associated with the estimates in this paper. It can be observed that lower taxes as a percentage of GDP, a smaller area, and a smaller population size, combined with a high degree of trade openness (high values of the trade openness variable) have been estimated to be associated with a greater likelihood of a country being a tax haven. The estimated coefficients can be 
Table 1: Database (raw variables)

\begin{tabular}{|c|c|c|c|c|c|c|}
\hline & Name & Source & Max & Min & Mean & Obs \\
\hline $\mathrm{X} 1$ & $\begin{array}{l}\text { Taxes } \\
(\% \text { GDP })\end{array}$ & $\begin{array}{l}\text { Worldbank Indicators; } \\
\text { IMF Statistics }\end{array}$ & 20.72 & 2.45 & 5.47 & 1595 \\
\hline $\mathrm{X} 2$ & $\begin{array}{l}\text { Population } \\
\text { (millions) }\end{array}$ & $\begin{array}{l}\text { Worldbank Indicators; } \\
\text { IMF Statistics }\end{array}$ & 326.265 & 0.148 & 1.232 & 1220 \\
\hline $\mathrm{X} 3$ & $\begin{array}{l}\text { Area } \\
\left(\text { millions of } \mathrm{km}^{2}\right)\end{array}$ & $\begin{array}{l}\text { Worldbank Indicators; } \\
\text { IMF Statistics }\end{array}$ & 17.982 & 0.132 & 1.03 & 1227 \\
\hline $\mathrm{X} 4$ & Trade Openness & $\begin{array}{l}\text { Worldbank Indicators; } \\
\text { IMF Statistics }\end{array}$ & 0.84 & 0.13 & 0.34 & 1195 \\
\hline $\mathrm{X} 5$ & $\begin{array}{l}\text { GDP growth } \\
(\%)\end{array}$ & $\begin{array}{l}\text { Worldbank Indicators; } \\
\text { IMF Statistics }\end{array}$ & 13.42 & -11.23 & -0.02 & 1195 \\
\hline Y1 & $\begin{array}{l}\text { Social contributions } \\
\text { (\% renevues) }\end{array}$ & $\begin{array}{l}\text { Worldbank Indicators; } \\
\text { IMF Statistics }\end{array}$ & 14.5 & 0.21 & 1.182 & 1195 \\
\hline Y2 & $\begin{array}{l}\text { Taxes on Goods } \\
\text { and Services (\% revenues) }\end{array}$ & $\begin{array}{l}\text { Worldbank Indicators; } \\
\text { IMF Statistics }\end{array}$ & 83.23 & 11.43 & 32.7 & 1195 \\
\hline Y3 & $\begin{array}{l}\text { Indirect Taxes / } \\
\text { Direct Taxes }\end{array}$ & $\begin{array}{l}\text { Worldbank Indicators; } \\
\text { IMF Statistics }\end{array}$ & 734.2 & 4.28 & 163.2 & 1195 \\
\hline Y4 & $\begin{array}{l}\text { Corruption Perception } \\
\text { Index }\end{array}$ & $\begin{array}{l}\text { Transparency } \\
\text { Internacional (2015) }\end{array}$ & 0.981 & 0.102 & 0.433 & 1195 \\
\hline Y5 & $\begin{array}{l}\text { Interests } \\
\text { (\% public expenditures) }\end{array}$ & $\begin{array}{l}\text { Worldbank Indicators; } \\
\text { IMF Statistics }\end{array}$ & 10.23 & 1.46 & 0.033 & 1195 \\
\hline Y6 & Democracy Quality Index & $\begin{array}{l}\text { Democracy Intelligence } \\
\text { Unit }\end{array}$ & 8.36 & 0.38 & 0.064 & 1198 \\
\hline
\end{tabular}

Table 2: Correlation Matrix

\begin{tabular}{rrrrrrrrrrrr}
\hline & \multicolumn{1}{c}{$(1)$} & \multicolumn{1}{c}{$(2)$} & \multicolumn{1}{c}{$(3)$} & \multicolumn{1}{c}{$(4)$} & $(5)$ & $(6)$ & $(7)$ & $(8)$ & $(9)$ & $(10)$ & $(11)$ \\
\hline$(1)$ & 1.0000 & & & & & & & & & & \\
$(2)$ & 0.0469 & 1.0000 & & & & & & & & & \\
$(3)$ & -0.2623 & 0.2876 & 1.0000 & & & & & & & & \\
$(4)$ & -0.2217 & 0.1301 & -0.2126 & 1.0000 & & & & & & & \\
$(5)$ & -0.3010 & 0.0004 & 0.2406 & -0.0251 & 1.0000 & & & & & & \\
$(6)$ & -0.4228 & 0.1574 & -0.0075 & 0.1415 & 0.2470 & 1.0000 & & & & & \\
$(7)$ & -0.0500 & -0.0043 & 0.0778 & 0.0590 & -0.2040 & 0.0573 & 1.0000 & & & & \\
$(8)$ & 0.1149 & -0.0207 & -0.1809 & -0.1336 & -0.1440 & 0.3747 & 0.5926 & 1.0000 & & & \\
$(9)$ & 0.1433 & -0.0139 & -0.0184 & -0.0691 & -0.0750 & -0.1701 & 0.0777 & 0.1234 & 1.0000 & & \\
$(10)$ & -0.2731 & 0.1321 & 0.1290 & 0.2150 & -0.0157 & 0.0627 & -0.0417 & -0.1152 & -0.2380 & 1.0000 & \\
$(11)$ & -0.0307 & -0.0346 & -0.1032 & -0.1129 & -0.0939 & -0.0399 & -0.1431 & -0.0247 & -0.0725 & 0.1235 & 1.0000 \\
\hline
\end{tabular}

Legend: (1) Taxes on goods and services (as a \% of revenues). (2) Indirect taxes / direct taxes. (3) Social security contributions (as a \% of revenues). (4) Interest (as a \% of public expenditures). (5) Population (millions). (6) Area of country (millions of $\mathrm{km}^{2}$ ). (7) Taxes (as a \% of GDP). (8) Trade openness. (9) GDP growth (\%). (10) Corruption Perception Index. (11) Democratic Quality Index.

interpreted following Dell'Anno and Mourao (2012): when the observed value for a given causal variable $x$ is significantly higher than its mean, the effect is observed to be greater on $y$ (the indicator vector of variables). Consequently, for instance, higher values of trade openness are related to significantly lower values observed for social security contributions as a proportion of public revenues as well as in reduced scores for a country's CPI. 
Table 3: Coefficients from MIMIC Models

\begin{tabular}{|c|c|c|c|c|}
\hline Model & $5-1-6$ & $4-1-6$ & $4-1-5$ & $4-1-4$ \\
\hline \multicolumn{5}{|c|}{ Causes } \\
\hline Taxes (\% GDP) & $\begin{array}{l}-0.575^{* * *} \\
(0.155)\end{array}$ & $\begin{array}{l}-0.580^{* * *} \\
(0.155)\end{array}$ & $\begin{array}{l}-0.683^{* * *} \\
(0.170)\end{array}$ & $\begin{array}{l}-0.794^{* * *} \\
(0.318)\end{array}$ \\
\hline Population (millions) & $\begin{array}{c}-0.198^{*} \\
(0.112)\end{array}$ & $\begin{array}{c}-0.198^{*} \\
(0.112)\end{array}$ & $\begin{array}{r}-0.253^{*} \\
(0.131)\end{array}$ & $\begin{array}{c}-0.325^{* *} \\
(0.145)\end{array}$ \\
\hline Area (millions of $\mathrm{km}^{2}$ ) & $\begin{array}{l}-0.737^{* * *} \\
(0.127)\end{array}$ & $\begin{array}{l}-0.744^{* * *} \\
(0.123)\end{array}$ & $\begin{array}{l}-0.742^{* * *} \\
(0.159)\end{array}$ & $\begin{array}{c}-0.750^{* *} \\
(0.272)\end{array}$ \\
\hline Trade Openness & $\begin{array}{c}0.816^{* * *} \\
(0.176)\end{array}$ & $\begin{array}{c}0.825^{* * *} \\
(0.172)\end{array}$ & $\begin{array}{l}0.887^{* *} \\
(0.201)\end{array}$ & $\begin{array}{l}0.918^{* *} \\
(0.392)\end{array}$ \\
\hline GDP growth (\%) & $\begin{array}{c}0.022 \\
(0.106) \\
\end{array}$ & Omitted & Omitted & Omitted \\
\hline \multicolumn{5}{|c|}{ Indicators } \\
\hline Social contributions (\% renevues) & $-0.328^{* *}$ & $-0.324^{* *}$ & $-0.343^{* *}$ & $-0.334^{* *}$ \\
\hline$\left[0.108 \leq \mathrm{R}^{2} \leq 0.111\right]$ & $(0.105)$ & $(0.108)$ & $(0.110)$ & $(0.124)$ \\
\hline Taxes on Goods and Services (\% revenues) & $0.707^{* * *}$ & $0.705^{* * *}$ & $0.581^{* * *}$ & $0.397^{* *}$ \\
\hline$\left[0.338 \leq \mathrm{R}^{2} \leq 0.500\right]$ & $(0.111)$ & $(0.112)$ & $(0.114)$ & $(0.199)$ \\
\hline Indirect Taxes / Direct Taxes & -0.153 & -0.154 & -0.153 & -0.179 \\
\hline$\left[0.028 \leq \mathrm{R}^{2} \leq 0.030\right]$ & $(0.113)$ & $(0.113)$ & $(0.102)$ & $(0.104)$ \\
\hline Corruption Perception Index & $-0.252^{* *}$ & $-0.246^{* *}$ & -0.174 & Omitted \\
\hline$\left[0.038 \leq \mathrm{R}^{2} \leq 0.063\right]$ & $(0.130)$ & $(0.129)$ & $(0.122)$ & \\
\hline Interests (\% public expenditures) & -0.339 & -0.305 & -0.288 & $\begin{array}{l}-0.296 \\
(0.281)\end{array}$ \\
\hline Democracy Quality Index & -1 & $\begin{array}{c}(0.153) \\
-1\end{array}$ & $\begin{array}{c}(0.459) \\
-1\end{array}$ & $\begin{array}{l}(0.281) \\
-1\end{array}$ \\
\hline \multicolumn{5}{|c|}{ Global goodness of fit statistics } \\
\hline Chi-square ( $p$-val) & $\leq 0.01$ & $\leq 0.01$ & $\leq 0.01$ & $\leq 0.01$ \\
\hline $\begin{array}{l}\text { Root Mean Square Error of Approximation, } \\
\text { RMSEA ( } p \text {-val) }\end{array}$ & 0.057 & 0.066 & 0.084 & 0.010 \\
\hline Overall $\mathrm{R}^{2}$ & 0.708 & 0.707 & 0.803 & 0.898 \\
\hline Number of obs. & 1040 & 1040 & 1330 & 1290 \\
\hline
\end{tabular}

Notes: Numbers between parentheses are standard errors. Statistical significance is denoted by ${ }^{* * *},{ }^{* *}$, and $*$ at the $1 \%, 5 \%$, and $10 \%$ levels, respectively.

\section{Results and Discussion}

The overall goodness of fit statistics are highly satisfactory. The test uses the RMSEA: a good fit is implied by a $p$-value higher than 0.05 (Browne and Cudeck, 1993), which is evident in Table 3. The chi-square values make it possible to reject the null hypothesis of non-conjoint significance of estimated coefficients for the causes and indicators in these models 2

Smaller countries and a reduced share of tax revenues as a percentage of GDP tend to be conditions more suited to a country assuming tax haven characteristics. Additionally, countries more exposed to international commerce are more likely to be identified as tax

\footnotetext{
${ }^{2}$ Observing the suggestion of Buehn and Schneider (2008), I also tested an alternative model considering the possibility of different long-run and short-run estimates. However, I did not find statistically significant differences between these latterly estimated values and the values in Table 3 Full results available upon request.
} 
havens. Independent of the number of causes ( 4 or 5$)$ or indicators $(4,5$, or 6$)$ included, these models also reveal that tax haven economies tend to decrease the level of contribution to social security (as a share of revenues).

\subsection{Robustness Checks}

To assess the robustness of these results, I follow Buehn and Schneider (2008). Given the correlation between the variables "trade openness" and "taxes as a percentage of GDP", these dimensions were combined into a single measure and the output structure was reassessed. Using the chi-square distribution table, the statistical value for the test represented a non-significant change at the 0.01 level of significance. Thus, the combination of the two dimensions into a single cluster was not warranted quantitatively and the output of the respective MIMIC model is not shown.

\subsection{Index of tax haven likelihood}

These results generally follow the outcomes from previous studies (Mourao and Raposo, 2013; Chavagneux and Palan, 2007) but also introduce direct and relevant challenges for further development. In particular, MIMIC models make it possible to extract scores from the latent variable, enabling researchers to produce an "index of likelihood of being a tax haven" with values for each country.

The estimates in Table 3 produce observed scores for the latent variable - the likelihood of being a tax haven (LTH) - for each of the 68 countries between 1990 and 2015. In Table 4 we exhibit the mean values across the observed period for the estimated coefficients for each country in each year. For greater readability, we present only the average LTH score for each country in Table 4 (full results are available upon request).

Table 4: Index of Likelihood of Being a Tax Haven (Average Scores, 1990-2015)

\begin{tabular}{|c|c|c|c|c|c|c|c|}
\hline MALAYSIA & 0.9672 & PANAMA & 0.338 & AUSTRIA & 0.0246 & $\begin{array}{l}\text { DOMINICAN } \\
\text { REPUBLIC }\end{array}$ & -0.2002 \\
\hline HUNGARY & 0.8867 & ROMANIA & 0.2481 & NICARAGUA & 0.0227 & LUXEMBOURG & -0.2425 \\
\hline TRINIDAD & 0.7202 & MALI & 0.2224 & BOLIVIA & 0.0222 & PERU & -0.2435 \\
\hline INDIA & 0.6474 & NETHERLANDS & 0.1841 & COSTA RICA & 0.0474 & RUSSIA & -0.3212 \\
\hline ITALY & 0.5929 & ICELAND & 0.1668 & CYPRUS & 0.0501 & US & -0.3352 \\
\hline CANADA & 0.5850 & NZ & 0.1641 & GUATEMALA & -0.0771 & $\begin{array}{l}\text { KOREA } \\
\text { SOUTH }\end{array}$ & -0.3518 \\
\hline CHILE & 0.5466 & IRELAND & 0.1400 & ISRAEL & -0.0750 & SLOVENIA & -0.3818 \\
\hline $\begin{array}{l}\text { SOUTH } \\
\text { AFRICA }\end{array}$ & 0.5186 & HONDURAS & 0.1489 & POLAND & -0.0949 & CZECH REP & -0.4168 \\
\hline SPAIN & 0.4770 & FIJI & 0.1237 & URUGUAY & -0.1049 & BULGARIA & -0.4298 \\
\hline MEXICO & 0.4328 & SRI_LANKA & 0.1230 & $\begin{array}{l}\text { EL } \\
\text { SALVADOR }\end{array}$ & -0.1786 & PHILIPINES & -0.463 \\
\hline SWEDEN & 0.3680 & GREECE & 0.0890 & ESTONIA & -0.1311 & & \\
\hline SWITZERLAND & 0.2720 & NORWAY & 0.0882 & PARAGUAY & -0.1584 & & \\
\hline AUSTRALIA & 0.2720 & COLOMBIA & 0.0797 & EQUADOR & -0.1761 & & \\
\hline
\end{tabular}


The results show that the average LTH score is low: 0.099 with a standard deviation of 0.356 (Table 4). This is a consequence of the de-meaning process used on the variables and for the latent dimension. However, it also means that positive values in the estimates of the index are more significant than negative values.

Nonetheless, some exceptional cases in Table 4 are worth discussing. For example, the minimum mean values are those of Venezuela, Nepal, and Germany. If the outflow of capital is clear evidence of the non-tax haven status of the first two, the presence of Germany in this group is explained by the level of German taxes as a proportion of public revenues as well as the high perception of corruption characterizing German society.

Although not all LTH scores are shown here, all were calculated for each year from 1990 to 2015, and for all 68 countries. However, the scores of Malaysia, Hungary, and Trinidad and Tobago serve as clear examples that validate the estimates of Table 4. In the period observed, these countries were reported as revealing serious issues in terms of tax competitiveness with reforms for enhancing the countries' attractiveness to foreign investors (Goldstein, 2009; Gravelle, 2015; OECD, 2015).

Other interesting cases relate to the position of economies like Denmark (15th) or Sweden (16th) which may seem high as those countries are among the countries with highest levels of taxation in the world whereas lower ranked countries such as Ireland (26th), Cyprus (42nd), and Luxembourg (56th) tend to be viewed as characterized by low income tax rates. However, note that the MIMIC framework is not based on just one dimension, for example, taxation level, and these index scores reflect variations in the latent variable.

\section{Conclusion and Further Challenges}

This paper researched the possibility of MIMIC models being used to contribute to the ongoing debate about the identification of a country as a tax haven. There is a current (and very diversified) effort to label countries in terms of more or less similarity to a pattern defined as that of a tax haven. This effort has mostly been undertaken by international organizations (e.g., the OECD or the IMF). However, this effort has been criticized because it has often identified a country as a tax haven by considering the set of agreements accepted by that country's ruling entities in terms of fiscal transparency, international delivery of data from banks' customers, and size of financial flows.

MIMIC models allow us to discuss the profile of a country in terms of its likelihood of being a tax haven. By considering the pressures from certain socio-economic dimensions such as the composition of public revenues or the pattern of international trade, this methodology allows us to work with latent dimensions (here, the propensity of a country to assume a profile of a tax haven) and with indicators, that is, variables which are changed because of the action of the latent dimensions.

Using data for 68 countries observed between 1990 and 2015, a panel data MIMIC 
approach was used. After the application of a robust set of procedures, the results of this work allow us to conclude that the tax burden, a country's area, its level of trade openness and population size are significant causes/sources of pressure to become a tax haven. The proportion of GDP corresponding to contributions to social security, the ratio of indirect to direct taxes, and the perception of corruption are robust indicators of tax havens.

One of the strengths of MIMIC models is the possibility of scoring a latent dimension. Therefore, for this paper, the MIMIC model methodology was used to generate an index describing to what degree a country is like a tax haven. The index provides values for scoring the likelihood of a country holding such a profile in each year of the observed period. Malaysia, Hungary, and Trinidad and Tobago had the highest likelihood scores across the years, whereas Venezuela and Nepal had the lowest scores on average.

We can identify two major implications from these results. The first implication is a theoretical one: it can be inferred that the phenomenon of tax havens is not a mere labeling process that depends on the organization in charge of the classification. A country becomes a tax haven in a (long historical) process in which its ruling institutions react to challenges from the surrounding economic structure and from endogenous social patterns. The second implication is an empirical one: the estimated scores show dynamic movement, meaning that countries assume more (or less) intense propensities for tax haven behavior according to a more (or less) defined profile of a tax haven; these propensities are not stable across an observed period.

This latter implication launches the first challenge: that it could be interesting to enlarge the focus of these results in order to detail the yearly evolution of the estimated scores for the latent dimension for each country. A second challenge relates to the opportunity to observe the degree to which these extractable scores correspond with reports from the OECD (2000) or International Monetary Fund (200). A third challenge regards the possibility of detailing the dimension of observed taxation, namely examining nominal corporate tax rates (or some measure of effective corporate rates) as causes. It must not be neglected that the overall value of tax revenues can be a problematic variable, as it can be associated with the level of overall economic development - in particular, less developed countries usually have low levels of tax collection (due to prevalent shadow economy activity and difficulties in collection). Therefore, as data become available to make it possible, it is suggested that the inclusion of detailed taxation data could serve as an enhancement to understanding the causes discussed in this paper. Additionally, dimensions like those proxying the banking sector size could also be explored, noting that current data availability does not allow this enhancement. Further research could also explore an enlarged discussion considering the possibility of reverse causation (observing, for instance, whether some of the indicators identified here can function as causes of the likelihood of being a tax haven). Finally, besides the opportunity to add other testable causes and indicators, a multi-way principal components analysis could be used as an alternative to the MIMIC models demonstrated here. 


\section{Acknowledgements}

The author acknowledges the suggestions provided by two anonymous reviewers. The author also acknowledges the suggestions provided by the participants at the 16th International Conference on Economics and Social Sciences (Tokyo, 9-10 March, 2019) and at the MIRDEC Conference (Madrid, 18-20 June, 2019). The author remains responsible for everything in this version of the document.

Compliance with ethical standards: This manuscript has been produced observing all relevant ethical standards.

Funding: This work was carried out with funding from (i) COMPETE reference $\mathrm{n}^{\circ}$ POCI01-0145-FEDER-006683, (b) Fundação para a Ciência e a Tecnologia, I.P. (FCT/MEC), and (c) the ERDF through the Operational Program on "Competitiveness and Internationalization - COMPETE 2020" under the PT2020 Partnership Agreement.

Conflict of interest: There is no conflict of interest.

Ethical approval: This manuscript has been produced observing all relevant ethical standards and the author assumes all the ethical claims.

Informed consent: The data used in this research did not require informed consent.

\section{References}

Becker, J. and Fuest, C. (2010). Tax enforcement and tax havens under formula apportionment. International Tax and Public Finance, 17(3):217-235.

Biondo, F. (2012). Basic Structure and Tax Havens. In Ballesteros, J., Fernández RuizGálvez, E., and Talavera, P., editors, Ius Gentium: Comparative Perspectives on Law and Justice. Globalization and Human Rights, volume 13, pages 27-49. Springer-Verlag, New York.

Bollen, K. A. and Brand, J. E. (2008). Fixed and random effects in panel data using structural equations models. UCLA CCPR Population Working Papers. Retrieved from: http://escholarship.org/uc/item/3sr461nd

Browne, M. W. and Cudeck, R. (1993). Alternative ways of assessing model fit. In Bollen, K. A. and Long, J. S., editors, Testing Structural Equation Model, pages 136-162. Sage, Beverly Hills, CA.

Buehn, A. and Schneider, F. (2008). MIMIC models, cointegration and error correction: An application to the French shadow economy. IZA Discuss Papers. IZA DP 3306.

Burn, G. (2006). The re-emergence of global finance. Palgrave Macmillan; UK.

Chavagneux, C. and Palan, R. P. (2007). Les paradis fiscaux. La Découverte, Paris, 2 edition. 
Chiarella, C., Pham, T. M., Sim, A. B., Tan, M., et al. (1992). Determinants of corporate capital structure: Australian evidence. Pacific Basin Capital Markets Research, 3:139158.

Dell'Anno, R. and Mourao, P. (2012). Fiscal illusion around the world: an analysis using the structural equation approach. Public Finance Review, 40(2):270-299.

Dell'Anno, R. and Villa, S. (2013). Growth in transition countries: big bang versus gradualism. Economics of Transition, The European Bank for Reconstruction and Development, $21(3): 381-417$.

Dharmapala, D. and Hines Jr, J. R. (2009). Which countries become tax havens? Journal of Public Economics, 93(9-10):1058-1068.

Dreher, A., Kotsogiannis, C., and McCorriston, S. (2007). Corruption around the world: Evidence from a structural model. Journal of Comparative Economics, 35(3):443-466.

Dybka, P., Kowalczuk, M., Olesiński, B., Torój, A., and Rozkrut, M. (2019). Currency demand and MIMIC models: towards a structured hybrid method of measuring the shadow economy. International Tax and Public Finance, 26(1):4-40.

Faith, N. (1984). Safety in Numbers: The Mysterious World of Swiss Banking. Hamish Hamilton, London.

Gravelle, J. (2015). Tax Havens: International Tax Avoidance and Evasion, Congressional Research Service 7-5700. In CRS Report Prepared for Members and Committees of Congress, Washington, DC, USA.

Hair, J. F., Anderson, R. E., Tatham, R. L., and Black, W. C. (1998). Multivariate Data Analysis with Readings. Englewood Cliffs, NJ: Prentice Hall, 5 edition.

Hines Jr, J. R. (2004). Do tax havens flourish? Technical report, NBER Working Papers 10936, National Bureau of Economic Research, Inc.

International Monetary Fund (200). Offshore Financial Centers (IMF Background Paper). Washington, DC: International Monetary Fund. Retrieved from http://www.imf .org/ external/np/mae/oshore/2000/eng/back.htm.

Jairo, I. (2008). The use of structural equation modelling (SEM) in capital structure empirical analysis. KCA Journal of Business Management, 1(1):11-35.

Jöreskog, K. G. and Goldberger, A. S. (1975). Estimation of a model with multiple indicators and multiple causes of a single latent variable. Journal of the American Statistical Association, 70(351a):631-639. 
Kuklys, W. (2004). Measuring Standard of Living in the UK - An Application of Sen's Functioning Approach Using Structural Equation Models. Papers on strategic interaction, Max Planck Institute of Economics, Strategic Interaction Group.

Maurer, B. (1997). Creolization redux: The plural society thesis and offshore financial services in the British Caribbean. New West Indian Guide/Nieuwe West-Indische Gids, $71(3-4): 249-264$.

Mourao, P. R. (2008). Towards a Puviani's fiscal illusion index. Hacienda pública española/Revista de Economia Publica, 187(4):49-86.

Mourao, P. R. and Raposo, A. M. (2013). Tax havens or tax hells? A discussion of the historical roots and present consequences of tax havens. Financial Theory $\&$ Practice, $37(3): 311-360$.

OECD (2000). Towards Global Tax Co-operation: Report to the 2000 Ministerial Council Meeting and Recommendations by the Committee on Fiscal Affairs: Progress in Identifying and Eliminating Harmful Tax Practices. Paris: OECD. Retrieved from http://www.oecd.org/tax/transparency/44430257.pdf.

OECD (2015). OECD Secretary General Report to G20, Finance Ministers, OECD, New York.

Rikowski, G. (2002). Globalisation and Education: A paper prepared for the House of Lords Select Committee on Economic Affairs, Inquiry into the Global Economy, 22nd January 2002.

Robinson, J. (1994). The Laundrymen - Inside the World's third largest business. Pocket Books: London.

Zellner, A. (1970). Estimation of regression relationships containing unobservable independent variables. International Economic Review, 11:441-454. 